\title{
ON SOME NON-SPECIFIC REACTIONS OF MALLEIN.
}

\author{
By H. J. SÜDMERSEN, Ph.D. ANd A. T. GLENNY, B.Sc.
}

(From the Wellcome Physiological Research Laboratories, Brockwell Hall, Herne Hill, London, S.E.)

\section{(8 Charts.)}

Ir has always been held by the veterinary profession that the mallein reaction is absolutely specific, although Schattenfroh in $1894^{1}$ claimed to have shown, as the results of some tests upon guinea-pigs, that mallein acted similarly to various bacterial proteins. In all cases the reaction was indicated by temperature since no swellings were obtained in guineapigs. The preparation (Foth's mallein) used by Schattenfroh was merely the proteins precipitated by alcohol from concentrated broth cultures of $B$. mallei, so that his conclusions do not apply to mallein as it is now prepared.

It has been recognised for some time that mallein causes a local swelling on horses suffering from purpura, but there is no rise in temperature, nor is the swelling a typical glanders reaction but disappears much more rapidly. The double reaction of both temperature rise and local swelling has been taken invariably to indicate glanders, although in some cases the local swelling alone is sufficient to condemn a horse.

The small rapidly disappearing swelling produced in normal horses has recently been used at these laboratories as an indication of the relative strengths of different samples of mallein. Owing to a lack of normal horses, a test ${ }^{2}$ was made of a fresh sample of mallein upon a healthy horse which had undergone treatment with diphtheria toxin for

1 “ Über die Wirkung von Bakterin-Proteinen," Zeitschr. f. Hygiene, Bd. xvır. p. 456, 1894.

2 The injections were all performed by H. J. Südmersen. 
over two years. This horse was chosen because at the time it happened to be resting after a period of treatment. The writers were greatly surprised to obtain a large local reaction and a rise of temperature sufficient to condemn the horse (see Chart I).

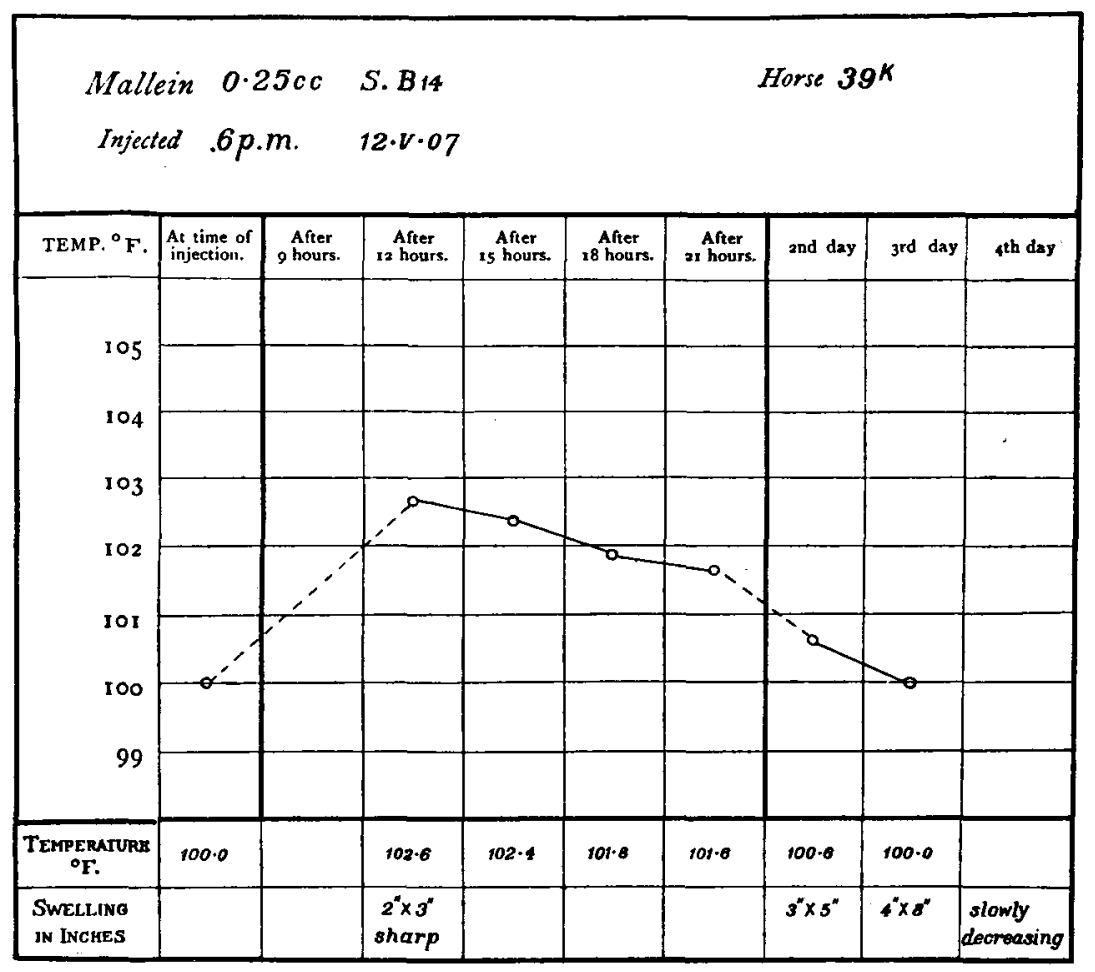

Chart I. First mallein reaction of horse $39 \mathrm{~K}$.

As the horse was well immunised and produced valuable antitoxin, it was decided to repeat the injection before condemning the animal. A second dose of 2 c.c. mallein (equivalent to twice the former dose) was injected within three days of the first injection. The local swelling produced was more marked than before and the temperature reaction was similar (see Chart II). After both injections of mallein the horse was "off his food and in low condition."

The reactions obtained were considered sufficient to condemn the horse as glandered, and on May 17th the horse was destroyed. Post-mortem examination was undertaken by Messrs Hunting and Humphrey, Veterinary Inspectors to the London County Council, but no trace of glanders could be found. On the 14th, cultures had been taken directly 
from the blood of the horse into broth, and on to agar and Loeffler slopes, but no growth took place. Two mice were injected with 0.5 c.c. each of fresh serum, and two guinea-pigs of 700 grams weight received 2 c.c. each, and no ill effects were observed in any of the animals.

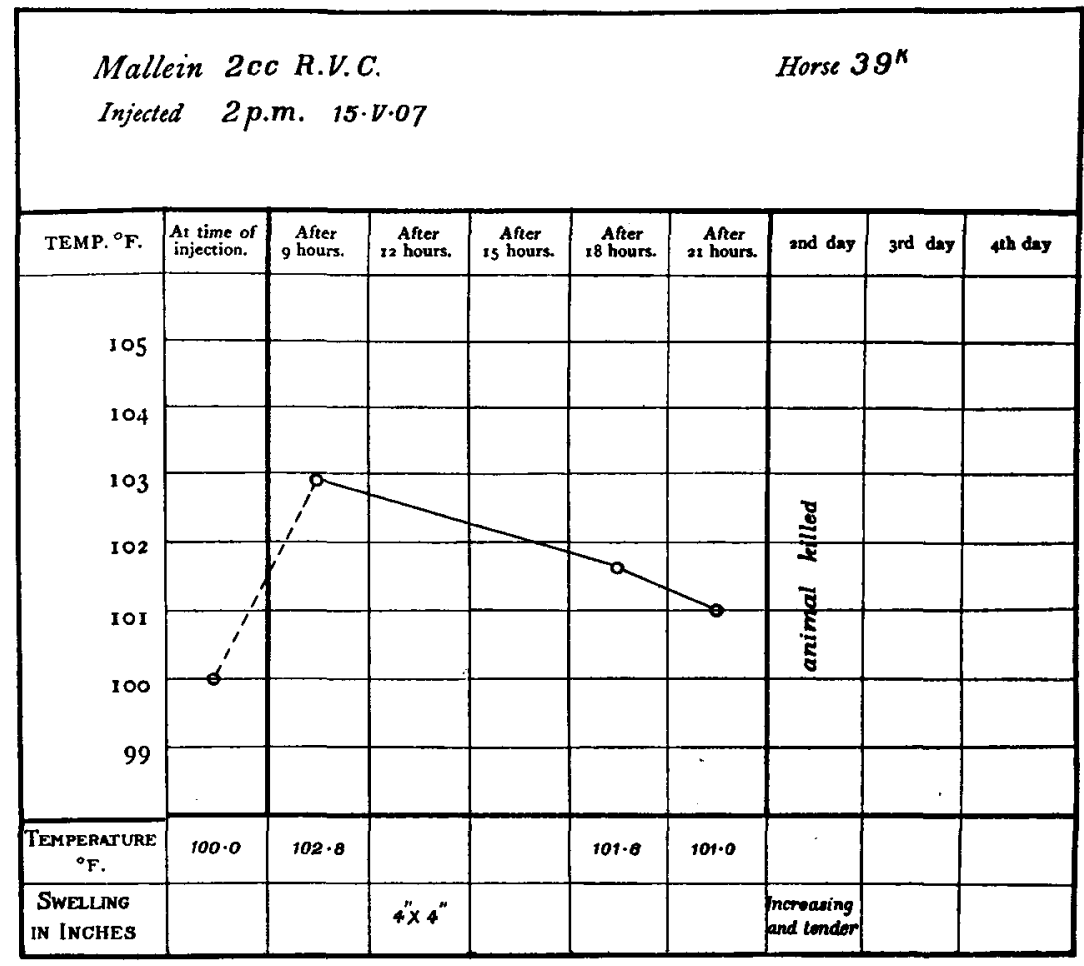

Chart II. Second mallein reaction of horse 39K.

On comparing the temperature curves of the foregoing horse (39K) with the average curves obtained from 19 horses (tested before admission to the stables), which gave both the local and temperature reaction and which, on post-mortem, were found to be glandered (see Chart III), it will be seen that the maximum rise in temperature in the case of horse $39 \mathrm{~K}$ corresponded exactly with the average rise in definitely glandered horses.

Comparing Charts I and II with Charts III and IV (the latter giving a typical temperature reaction for a glandered horse) it will be noted that the general slope of the curves is different. In glandered horses the highest temperature is apparently reached 15 hours after the injection of mallein and the fall in temperature is gradual. In the case 


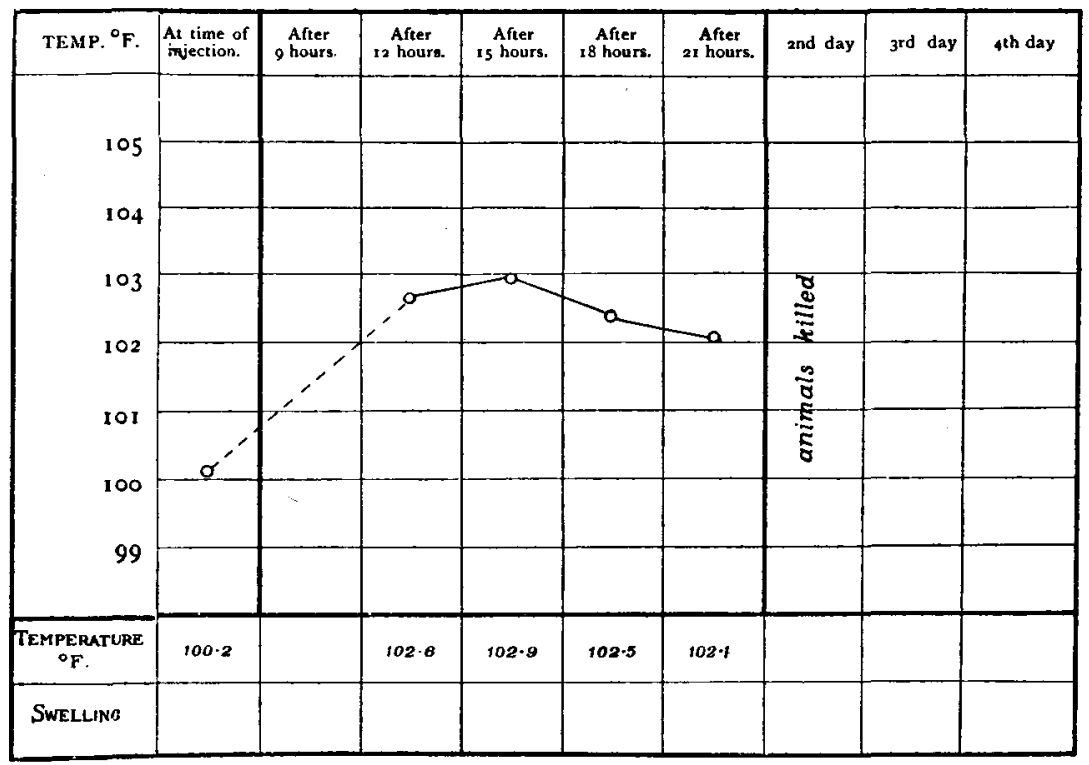

Chart III. Average temperatures of 19 glandered horses which gave large local reactions.

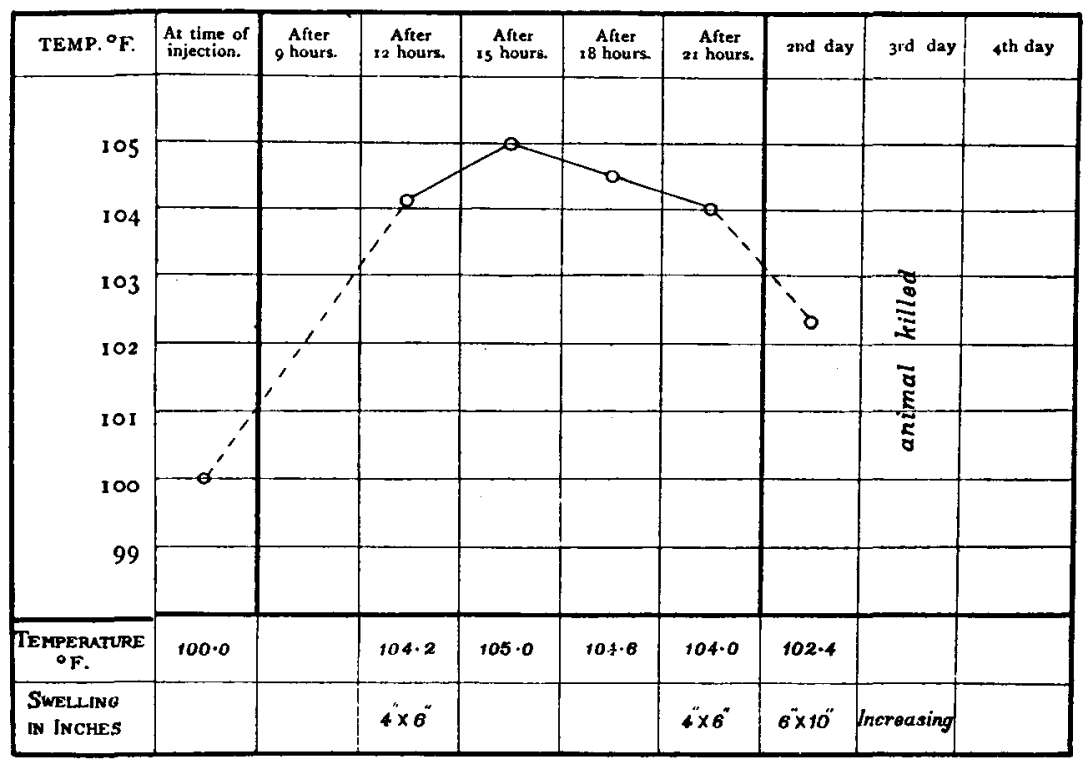

Chart IV. Typical mallein reaction of a glandered horse (No. 52H). Journ. of Hyg. vIII 
of horse $39 \mathrm{~K}$ the bighest temperature was reached 9-12 hours after injection and the fall in temperature was comparatively rapid. The local swelling did not increase very rapidly but became more diffuse than is the case with most glandered horses.

The temperature reaction in the case of mallein is of great help in diagnosing glanders, but must rank of secondary importance compared with the local swelling. Chart $\mathrm{V}$ gives the average temperature of seven horses, tested before admission to the stables, which gave decided local swellings but no large rise in temperature.

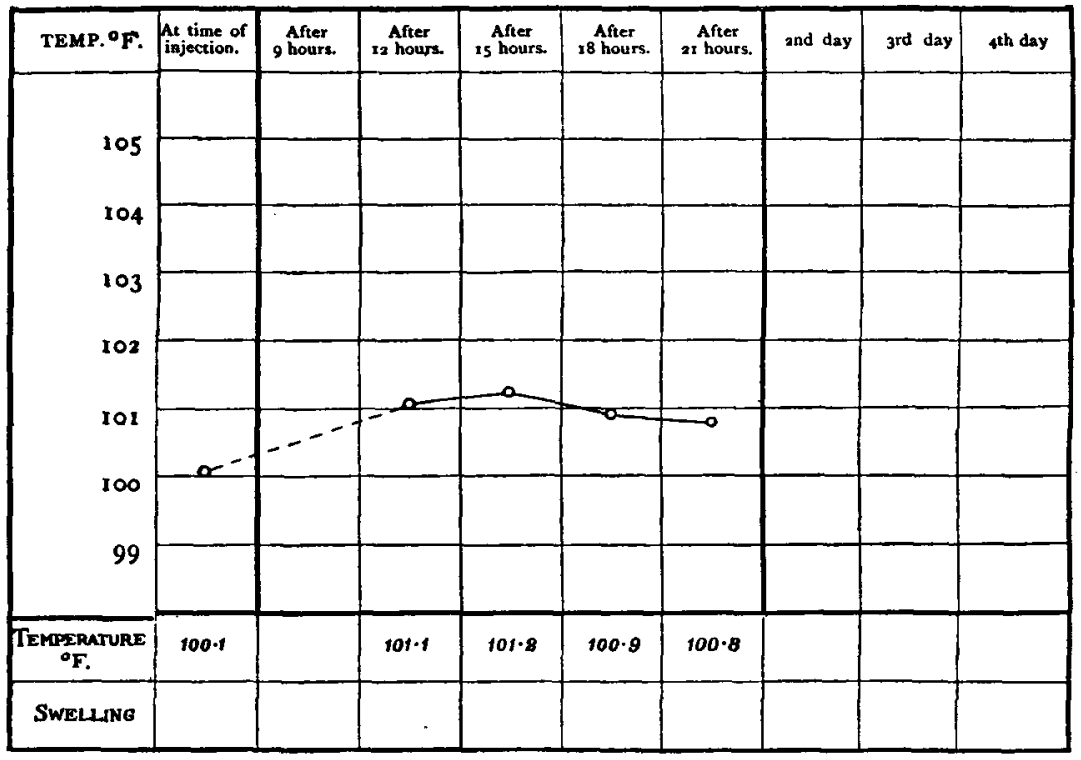

Chart V. Average temperatures from 7 glandered horses which gave large local reactions with very little rise in temperature.

These were condemned as glandered and in all seven cases postmortem examination showed the correctness of the diagnosis. Although a rise of only one degree was obtained, yet again it is noticed that the highest temperature is after 15 hours and that very little fall takes place in the temperature during the next few hours.

When horse $39 \mathrm{~K}$ was originally bought it was subjected to the mallein test and passed satisfactorily (see Chart VI).

Since that time the horse had not been exposed to any possibility of infection with glanders.

It was thought that the reaction obtained with horse $39 \mathrm{~K}$ might 
be due to the fact that the horse had been treated with diphtheria toxin for two years. Further experiments were therefore carried out to determine whether a reaction was always obtained upon injecting with mallein horses which had been previously immunised against diphtheria toxin or other bacterial products.

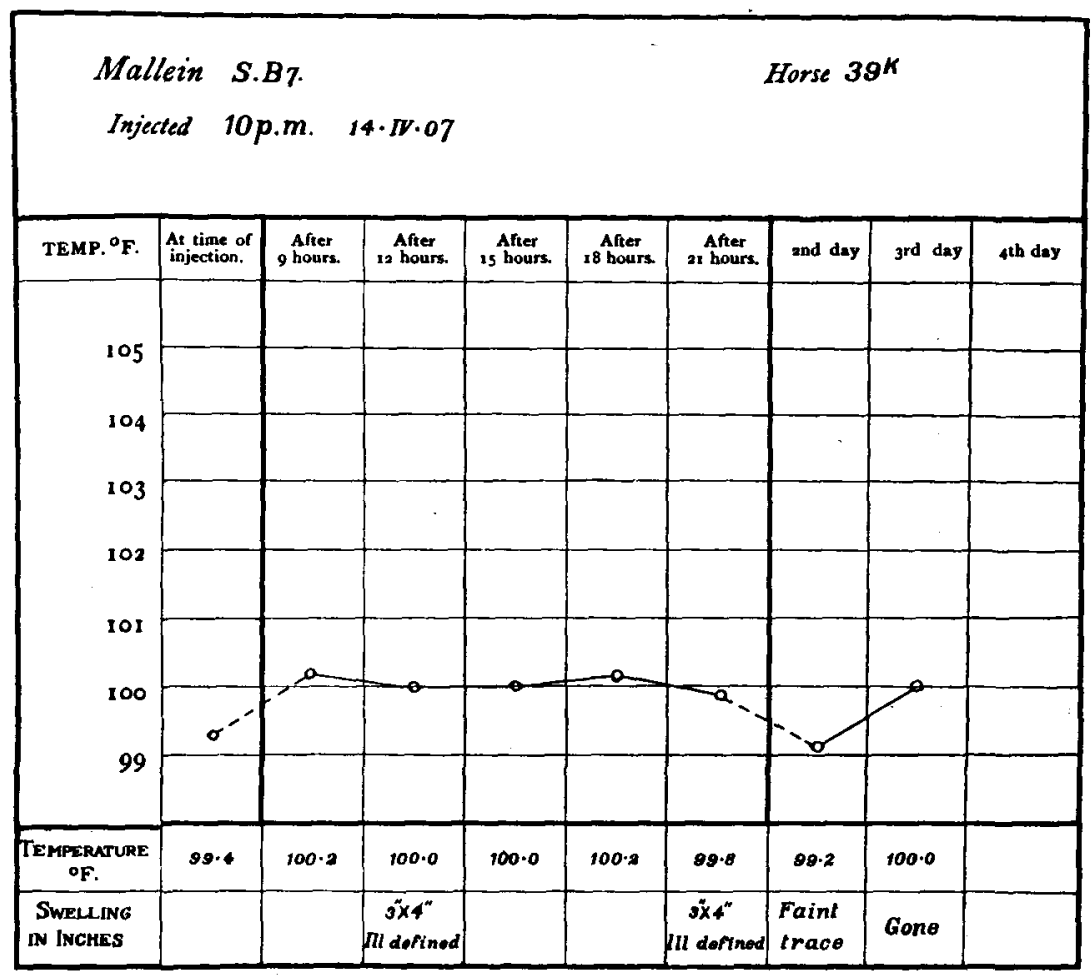

Chart VI. Original mallein reaction of horse $39 \mathrm{~K}$.

The Action of Mallein upon Immunised Horses.

The experiment was repeated on a large number of immune horses, with the result that a number of them showed large local swelling but usually no temperature reaction. At the end of twelve hours the local swelling is quite typical of a glanders reaction, but at the end of 24 hours it has commenced to disperse although in some instances it remains large but diffuse until the end of the second day.

Table I gives the results obtained by injecting mallein into 56 horses in various stages of immunisation. The last three columns give the 


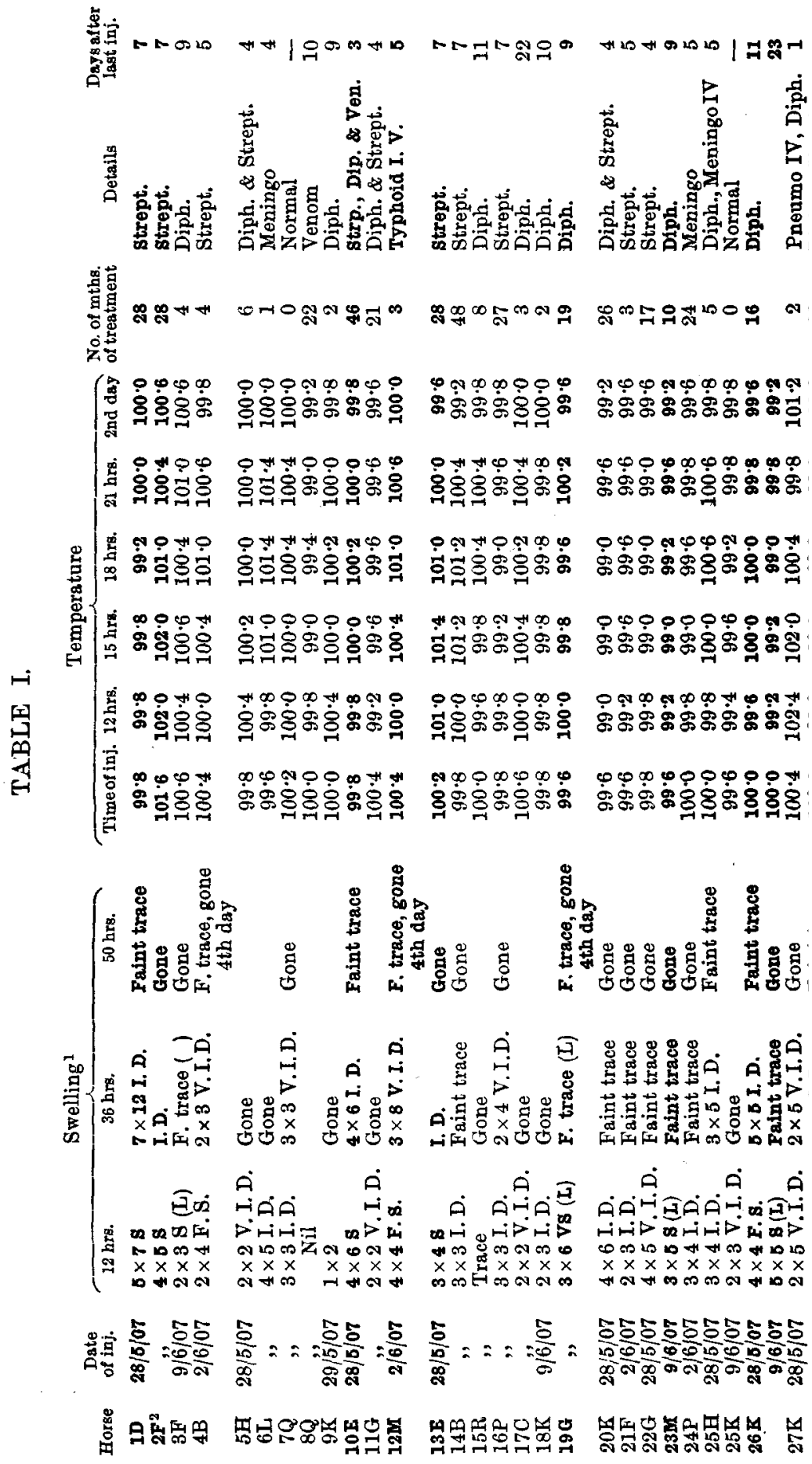




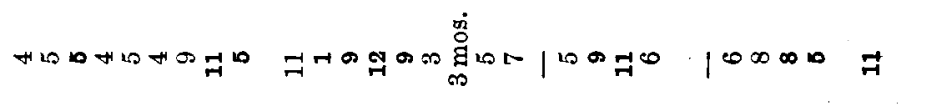

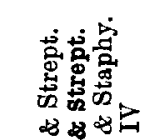

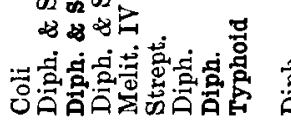

यूล

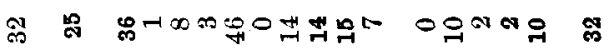

0

Oب

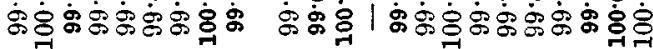

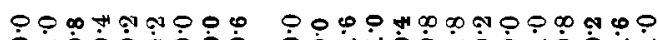

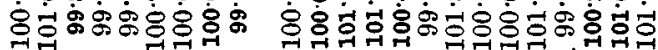

\section{ب}

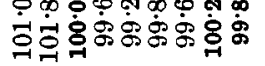

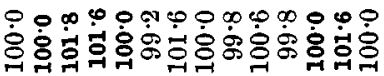

迹

हैं

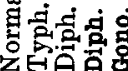

ำ

த் $\dot{\sigma} \dot{\sigma} \dot{\circ} \dot{8} \dot{8}$

م ச் $\dot{8} \dot{8} \dot{8} \dot{8}$

$\infty \infty \infty \infty 0$

த்த்த்த்

*

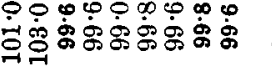

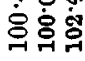

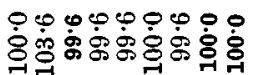

ம

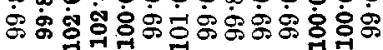

ب

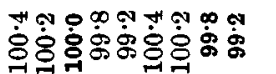

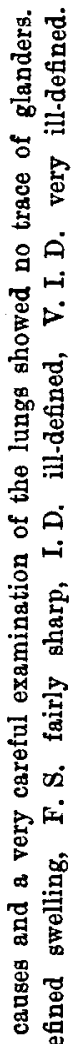

คศัฺำ

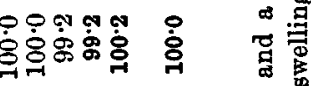

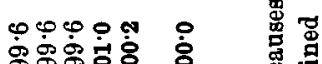

岁荌

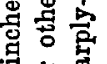

용 염

呇

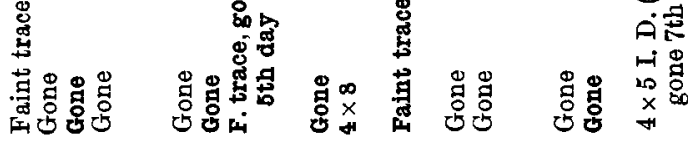

. क्ष

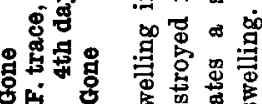

总安察要

通

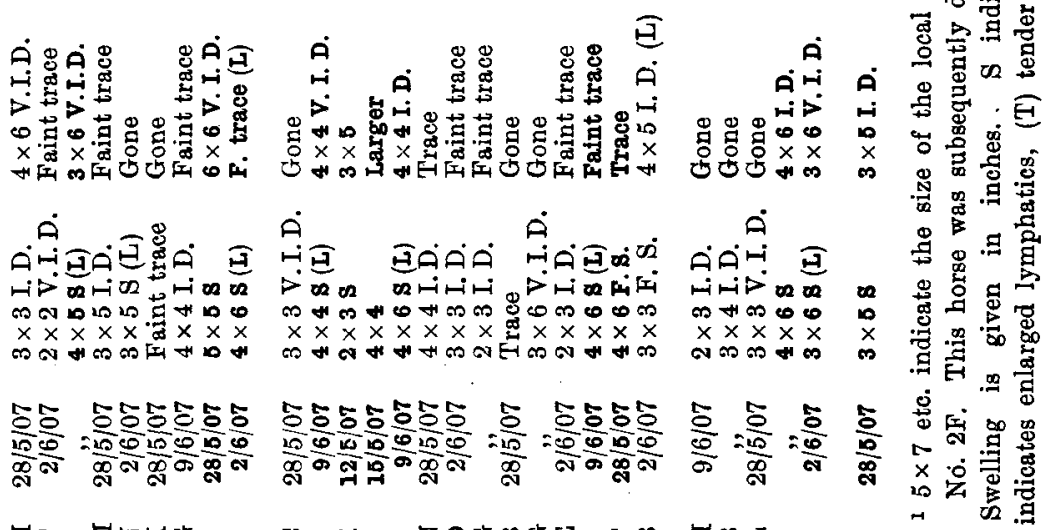

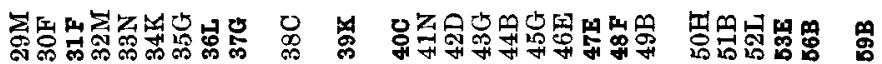


number of months of treatment, description of toxin or organism used, and the number of days since the last injection.

It need hardly be added that none of these horses reacted to mallein before treatment, no horse being introduced into the stables unless it has satisfactorily passed the test.

It will be noticed that a large number of these horses gave decided local swellings. An analysis of the results shows that the size of swelling in general depends on the degree to which the horse has been immunised.

In the following tables the reactions are divided as follows:-

Large reaction. Well-defined sharp swellings over $3 \times 3$ or illdefined swellings over $4 \times 4$ (inches).

Medium reaction. Any well-defined swelling under $3 \times 3$; an ill-defined swelling of $4 \times 4$ or any swelling not dispersing rapidly.

Small reaction. Any ill-defined swelling under $4 \times 4$ dispersing rapidly.

\section{Horses immunised against Diphtheria Toxin.}

In Table II the results are tabulated for all horses that have been used solely for the production of diphtheria antitoxin serum.

TABLE II. Horses injected with diphtheria toxin, grouped according to length of immunisation.

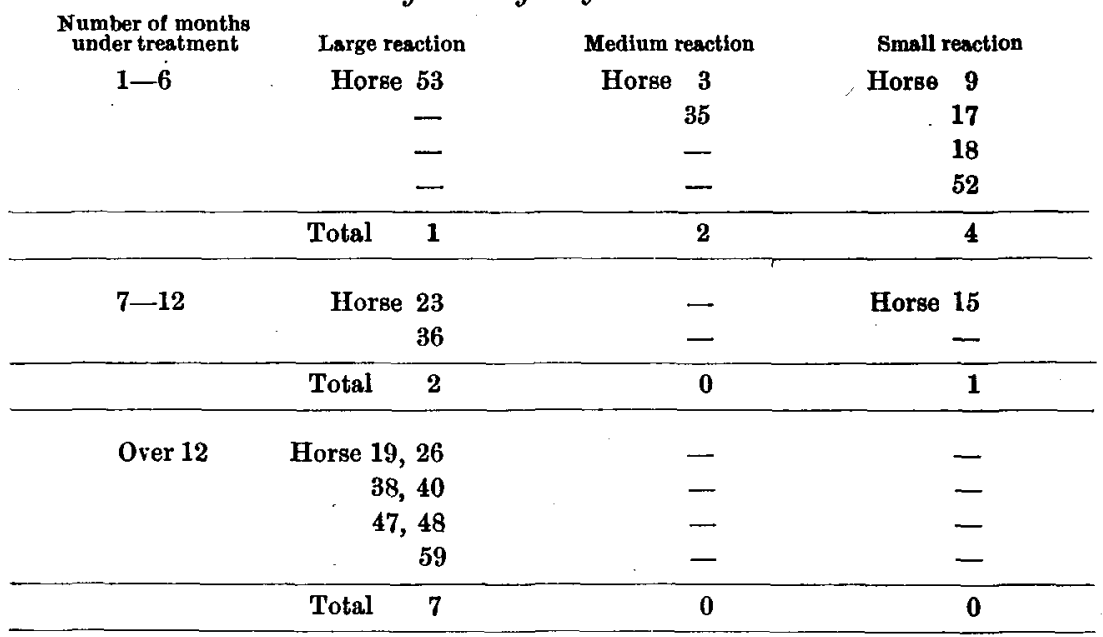

From this table it will be seen that all horses that have been immunised with diphtheria toxin for over twelve months give large local 
reactions with mallein. Of the horses that have been treated for periods of less than six months numbers $9,17,18$, and 52 , which give little or no swelling, are all of very low antitoxic value, while horse 53 with a large swelling has undergone the same treatment, but has yielded comparatively high value serum (600 units per c.c.) for so short a time (2 months). Subsequently (after three months' treatment) this horse yielded serum of 1700 unit value.

Horses 3 and 35 have yielded medium value serum and both give medium reactions. Table III gives the results grouped according to the antitoxic value of the horses.

TABLE III. Horses injected with diphtheria toxin, grouped according to antitoxic value.

\begin{tabular}{|c|c|c|c|}
\hline \multirow{5}{*}{$\begin{array}{l}\text { Antitoxic value } \\
\text { Under } 250 \text { units } \\
\text { per c.c. }\end{array}$} & \multirow{2}{*}{$\begin{array}{c}\text { Large reaction } \\
-\end{array}$} & \multirow{2}{*}{$\begin{array}{c}\text { Medium reaction } \\
-\end{array}$} & Small reaction \\
\hline & & & Horse 9 \\
\hline & - & - & 17 \\
\hline & - & - & 18 \\
\hline & - & - & 52 \\
\hline & Total & 0 & 4 \\
\hline \multirow[t]{2}{*}{$250-400$} & - & - & - \\
\hline & Total & $\mathbf{0}$ & 0 \\
\hline \multirow[t]{5}{*}{$400--600$} & Horse 26 & Horse $\mathbf{3}$ & Horse 15 \\
\hline & 38 & 35 & - \\
\hline & 47 & - & - \\
\hline & 53 & - & - \\
\hline & Total & 2 & 1 \\
\hline
\end{tabular}

\begin{tabular}{|c|c|c|c|}
\hline Over 600 & $\begin{array}{r}\text { Horse } 19 \\
23 \\
36 \\
40 \\
48 \\
59\end{array}$ & $\begin{array}{l}\bar{z} \\
\bar{z} \\
\bar{z}\end{array}$ & $\begin{array}{l}\bar{I} \\
\bar{I} \\
\bar{I}\end{array}$ \\
\hline & Total & 0 & 0 \\
\hline
\end{tabular}

The result obtained with horse 15 seems out of accord with the other results, for although this horse has yielded serum of value between 400 and 600 units per c.c. for the past eight months, yet no reaction was obtained with mallein. Horse 38 gave a similar result at the first injection but subsequently when the injection was repeated it gave a large reaction. 
From these results it appears that the size of the mallein swelling is related to the antitoxin producing power of the horse. It is possible that the length of treatment after the horse has once been immunised has little effect upon the swelling and that the results recorded in Table II are due to the fact that no horses are kept for any length of time unless they are yielding high value serum. It is well known that the antitoxin producing capacity of a horse reaches a maximum, and that after varying lengths of time there is a gradual diminution of value until comparatively little antitoxin is produced. Experiments will be carried out to ascertain whether the horses in this condition will react or not to mallein.

\section{Horses immunised against Bacteria and their Products other than Diphtheria Toxin.}

These results are not so uniform as those obtained with the horses used for the production of diphtheria antitoxin. In no case has any horse which has been under treatment for less than six months given a large reaction, but several horses failed to react to mallein after over three years' Streptococcus treatment. Further experiments are being carried out to ascertain whether, during a prolonged course of treatment, horses, having passed the stage when their reaction (to mallein or other substances) has been at a maximum, finally reach a stage at which their reactivity decreases or even disappears. In the case of diphtheria antitoxin production, this is of regular occurrence, and after varying lengths of time high value horses become comparatively useless. A similar state may be reached in diphtheria horses by overdosing and an example of this occurs amongst the horses used for the production of bactericidal sera. Number 32 once received, by mistake, a large overdose of Staphylococcus, after this the animal was useless for the production of antisera. The opsonic index to Staphylococcus remained constantly below normal. This horse gave no reaction to mallein.

The general indications are that during the first few months of treatment no mallein swelling is obtained, but that, when once it is well immunised, the animal will react. Also it would appear that after some time, depending partly upon the constitution of the horse and partly upon the nature of its treatment, it ceases to react. Horses under very severe treatment such as Meningococcus (No. 24) and B. dysenteriae (No. 46) failed to react after over two years' treatment. This indicates a paralysing effect upon the reacting capacity of the animal, but that 
the horse is still capable of producing antibodies is shown by the high opsonic index and good clinical results still obtained with the serum of number 24:

The results are not confined to horses treated with subcutaneous injections. Of the horses injected intravenously numbers 12 and 43 form a good contrast; both have been immunised against typhoid endotoxin for the same length of time (3 months) but borse 43 can now tolerate over ten times as much as number 12 , and its temperature reaction is usually much lower. On comparing the mallein results of these two horses it is seen that 12 gives a marked reaction and 43 gives none. The protective value of the serum from these two horses does not show any marked difference, and the opsonin, agglutinin and precipitin values closely agree.

In the case of one horse (No. 8) which has been injected with venoms and not with any bacterial products, no mallein reaction was obtained although the horse is capable of producing high value antivenin. The other (No. 10) injected with venoms had been previously treated with bacterial products and now gives a large swelling with mallein.

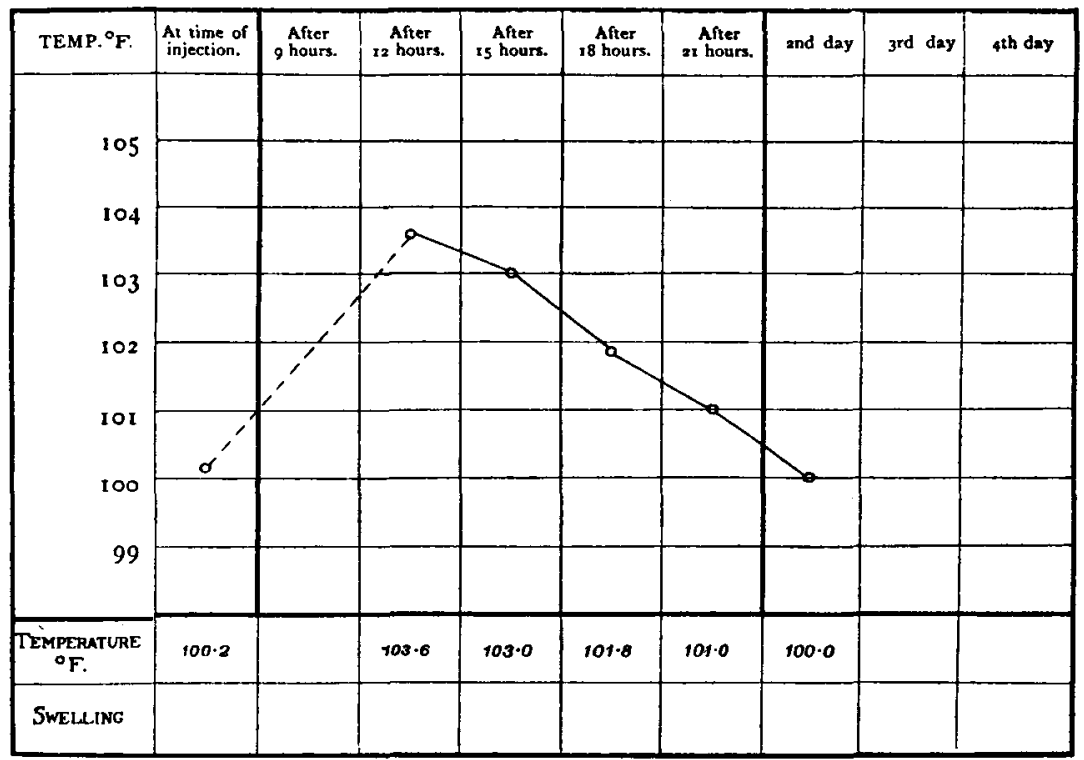

Chart VII. Mallein reaction of horse 30 . 


\section{The Temperature Reactions.}

In only a few instances has there been any marked temperature reaction. In the original case of horse $39 \mathrm{~K}$ there were both local reaction and rise in temperature; horse $30 \mathrm{~F}$ (after 39 months of treatment) gives a rise of over $3^{\circ} \mathrm{F}$. but no local reaction. In the case of horse 27 the temperature rise may be accounted for by the fact that the horse received the dose of mallein on the day after an injection with diphtheria toxin. The temperature curves of these two horses are plotted in Charts VII (horse 30) and VIII (horse 27).

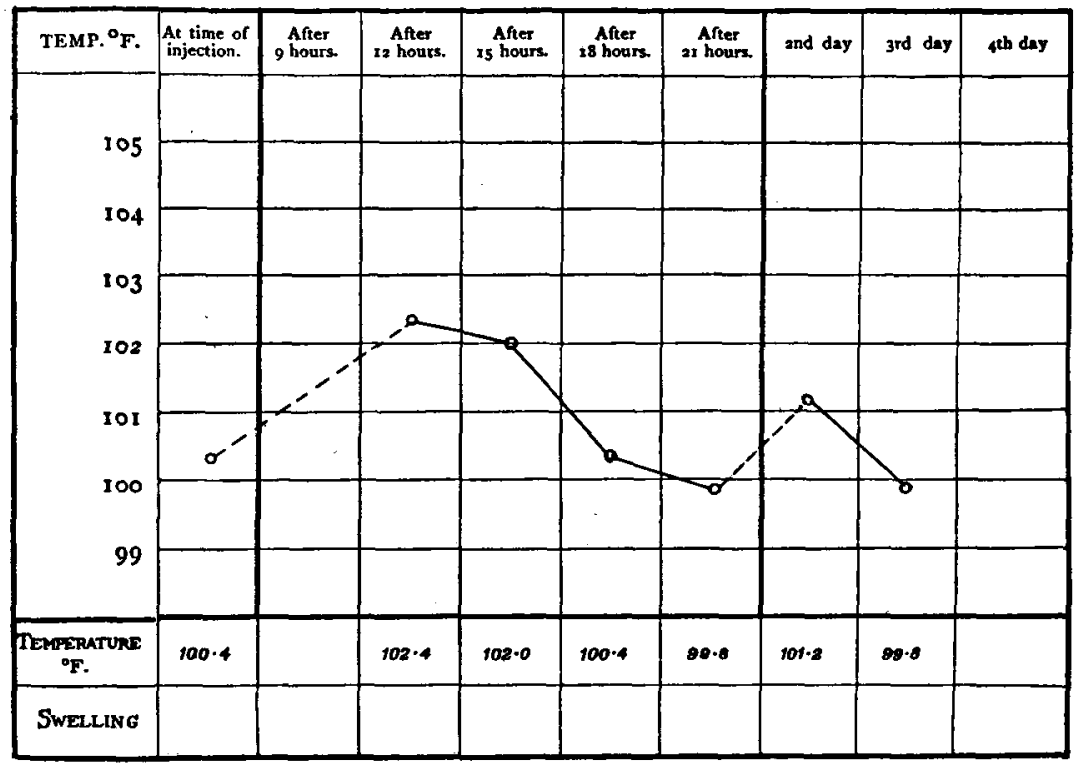

Chart VIII. Mallein reaction of horse 27.

It will be noticed that they resemble the horse $39 \mathrm{~K}$ curve (Charts I and II) in their rapid fall. The other horses to give a rise of over $1^{\circ} \mathrm{F}$. were 13 (Streptococcus) and 48 (B. diphtheriae), which also gave local reactions, 6 (Meningococcus) and 49 (B. diphtheriae) with medium swellings, while 14 (after 4 years' Streptococcus treatment) and 42 (on intravenous treatment) gave no local reactions. 


\section{Action upon Immune Horses of Bacterial Products other than Mallein.}

A series of experiments were carried out to ascertain whether other bacterial products injected hypodermically into immune horses cause local reactions similar to those obtained with mallein.

In these experiments the horses were mostly injected on both sides of the neck with different products. This has been our regular proceeding when testing the relative strength of different batches of mallein and we have never found an injection upon one side of the neck to affect the local reaction upon the other side. In these experiments the temperature results cannot be of much importance as any rise in temperature may be due to either or both of the injections. We have noticed that two injections of mallein cause no higher rise than a single dose.

In the following tables the last column records the nature of the injection upon the other side of the neck to that upon which the horse was injected with the product dealt with in the table. Details of the previous treatment of the horses are given in Table $\mathbf{I}$.

\section{Tuberculin.}

Table IV gives the results of injecting 13 horses with tuberculin. Large local reactions were obtained with horses $1,2,10,28,36,38$, all well immunised horses; horse 26 gave nil at first but a large swelling resulted from repeating the dose, and horse 44, a well immunised Streptococcus horse, gave only a small reaction. The other horses giving small reactions had been under treatment for only a short time. All horses satisfactorily passed the tuberculin test before admission to the stables.

\section{Coli Products.}

In these experiments the filtrate was used from a three months old broth culture of $B$. coli. One-tenth of a c.c. was found sufficient to give decided local reactions with well immunised horses such as Nos. 2, 10, $13,36,48$, and 59 , but only small swellings were obtained with No. 7 (normal), 8 (venom), 45 (normal), and 52 (low value diphtheria horse). Numbers 14 (Streptococcus), and 38 (diphtheria), were the only well immunised horses that failed to give a local reaction. Horse 48 (diphtheria) again gave a rise of over $1.0^{\circ}$ in temperature (see mallein results, Table I). Horse 29M, which had been treated for the past five months with killed cultures of $B$. coli, gave a fairly sharp reaction, more marked than was the case in the mallein test.

Full details of these results are recorded in Table V. 


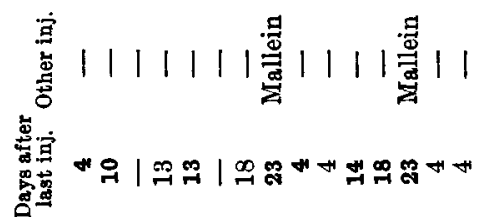

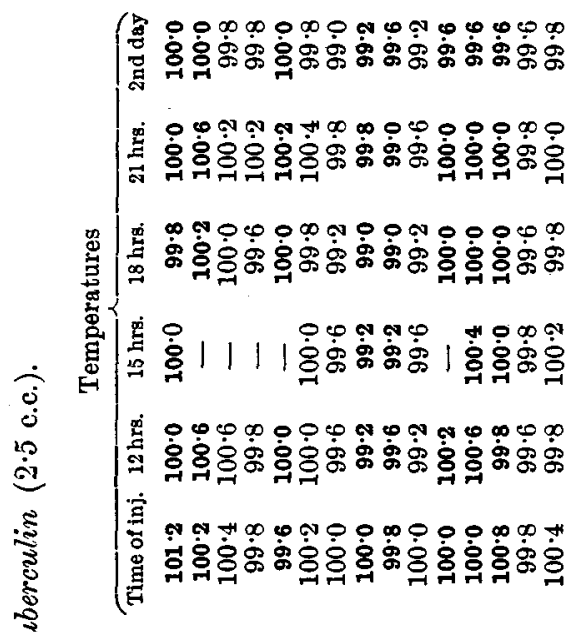

䓃

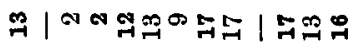

0

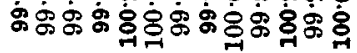

웅ำ

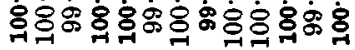

|

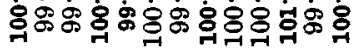

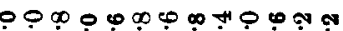
审审审

مب ب

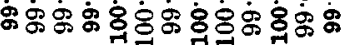

ப 审宁

iั

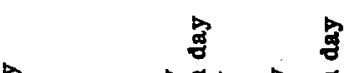

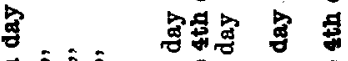

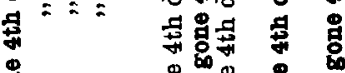

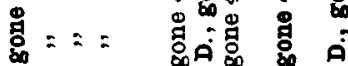

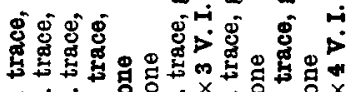

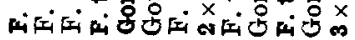

已 $\dot{A} \dot{A}$.

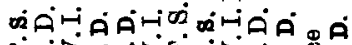

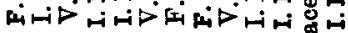

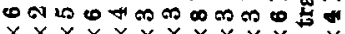
$\times \times \times \times \times \times \times \times \times \times \times \times$

\section{코롭}

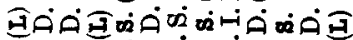

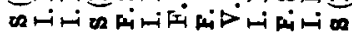
ด $\times \times \times \times \times \times \times \times \times \times \times \times \times$

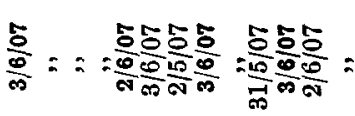

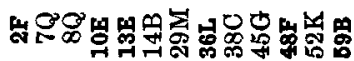



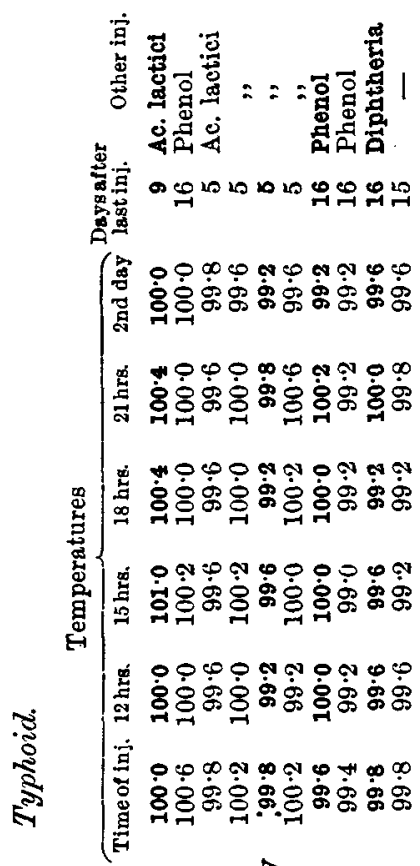

空
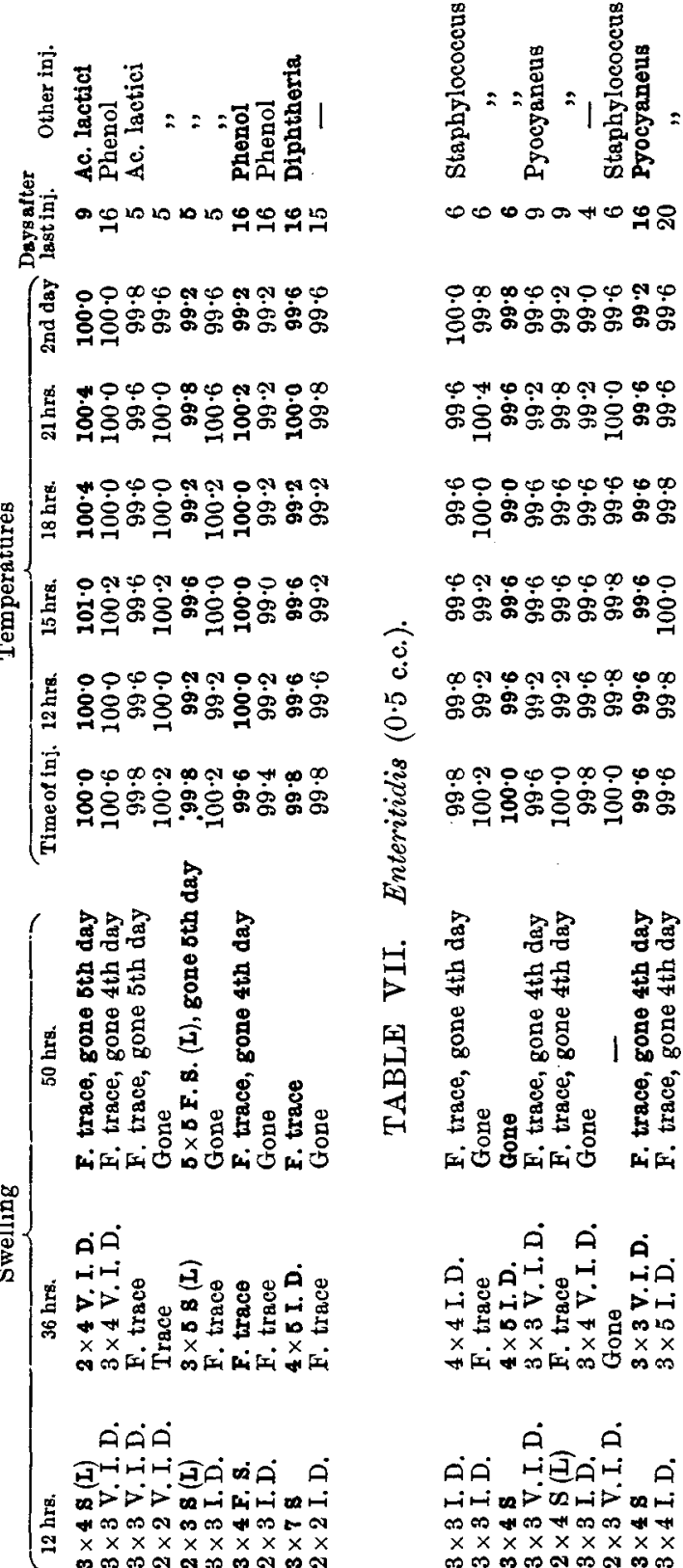

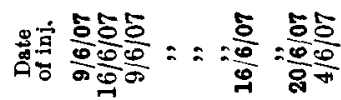

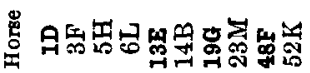

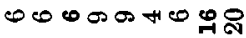

ب

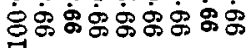

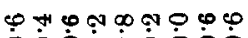

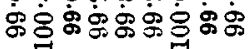

000000000

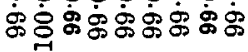

$\varphi$ Q

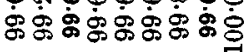

ب0

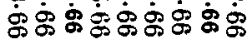

$\infty \div \circ \div \circ \% \circ \varphi$

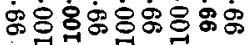

急 急完

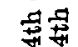
造量 1 60

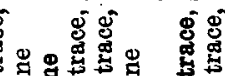

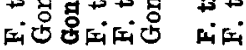

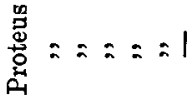

00 a do a 000

000000

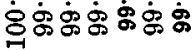

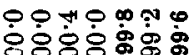
억응요요용

잉ำ

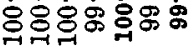

$000 \pi 0 n$

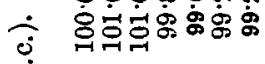

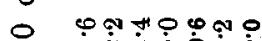
ㄴㅎㅇㅎㅇ요용

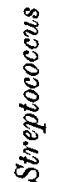

$000 \varphi 0 \infty$

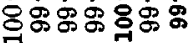

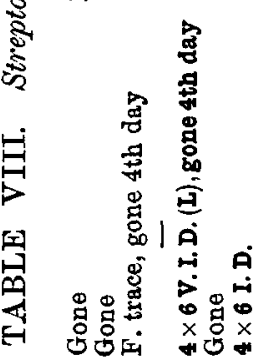

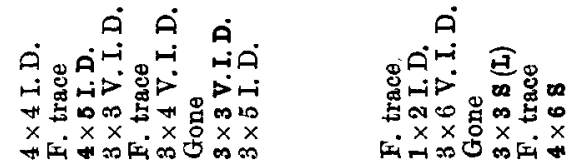

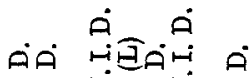

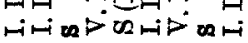
$m$ का $x \times \times \times \times \times \times \times$ m

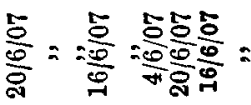

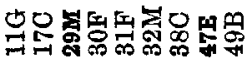

$\dot{\theta}$

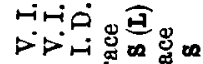
$\infty \infty$ 年 $\times \times \times \times$ $\sum_{0}^{5}=a=a n=$

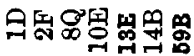




\section{Typhoid.}

A half c.c. of the filtrate from a three months old broth culture of B. typhosus was used.

Large swellings were obtained with horses 1 and 13 (Streptococcus), 19 and 48 (diphtheria); all four of these horses had been immunised for a long period. Two well immunised horses, Nos. 14 (Streptococcus) and 23 (diphtheria) gave only small reactions. Comparing the swellings caused by the typhoid products with that caused by mallein, only in the case of horse 23 (diphtheria) is there any discrepancy. In no case was there any temperature reaction. Details of results are recorded in Table VI.

\section{Enteritidis.}

In Table VII are recorded results obtained by injecting immune horses with 0.5 c.c. of the filtrate from a three months old broth culture of B. enteritidis. The only horses to yield well marked reactions were Nos. 31 (Streptococcus), 47 (diphtheria), both well immunised horses which had reacted strongly to mallein, and horse $29 \mathrm{M}(B$. coli $)$. The reaction of the last horse was more marked after injecting with $B$. enteritidis than with $B$. coli. The well immunised horses failing to react were No. 30, which also gave only a small swelling with mallein, and No. 38, which reacted to mallein but not to $B$. coli products.

\section{Streptococcus.}

The results obtained with 1 c.c. filtered broth cultures of Streptococcus (of from one to three months' growth) differed somewhat markedly from those obtained with any other bacterial products. Horses 1, 2, and 10 immunised against Streptococcus all failed to react, although all these had given decided swellings with mallein and tuberculin, and typhoid or coli products; No. 13, the only other Streptococcus horse tested, gave a sharp swelling. In the case of horse 2 , there was a rise in temperature of $2 \cdot 4^{\circ} \mathrm{F}$., but this horse received 0.5 c.c. proteus products at the same time as the Streptococcus injection, so that it is not possible to say which injection caused the temperature reaction. The results are recorded in Table VIII.

\section{Staphylococcus.}

One c.c. of the filtrate from a three months old culture of various strains of Staphylococcus pyogenes aureus produced swellings similar to those obtained with mallein with one exception; horse 32 (immunised 
against Staphylococcus) gave no reaction with mallein but responded to the injection of Staphylococcus products. The details of the results are given in Table IX.

\section{Diphtheria.}

Moderately weak diphtheria toxin was used in doses of 0.5 c.c. The only horses to react were those which had been immunised against diphtheria toxin, numbers 32,36 , and 48 ; in the case of number 32 , no reaction was obtained with mallein. This result is particularly interesting in consideration of the fact that the dose of toxin used together with less than one five-hundredth of a c.c. of the serum from either 36 or 48 would cause no swelling in a guinea-pig. Both horses 10 and 37 which had reacted to mallein failed to react to diphtheria toxin. In no case was there any temperature reaction. The results are recorded in Table $\mathrm{X}$.

\section{Proteus.}

Very marked reactions resulted from injecting horses 1 and 13 with 0.5 c.c. of the filtrate from a three months old growth of B. proteus on broth. The general results obtained differ considerably from the result of the mallein injection. Horse 8 (venom) gave a reaction while horses 2 (Streptococcus) and 36 (diphtheria) failed to do so. It is interesting to note that proteus is the only bacterial product which has given a reaction on horse 8.

A rise in temperature occurred in the case of horse 2 which received an injection of Streptococcus products at the same time as the proteus injection. The results are recorded in Table XI.

\section{Pyocyaneus.}

Table XII gives the results of injecting 02 c.c. of a three months old filtered broth culture of $B$. pyocyaneus. High temperatures were obtained with horse 7 , injected at the same time with 1 c.c. of $2.5 \%$ phenol; this may be due to the considerable exercise which the horse endured shortly after injecting, and during the following day. Horses 2 (Streptococcus) and 47 (diphtheria) were the only animals to produce well-defined swellings. Well immunised animals such as 10, 20, 30, 31, all failed to react.

\section{Acidi Lactici.}

The filtrate from a three months' growth on broth of B. acidi lactici was used in doses of 0.2 c.c. Table XIII shows that the results do not differ from those obtained after injecting mallein. 


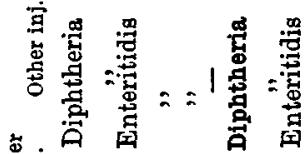

这家 票总

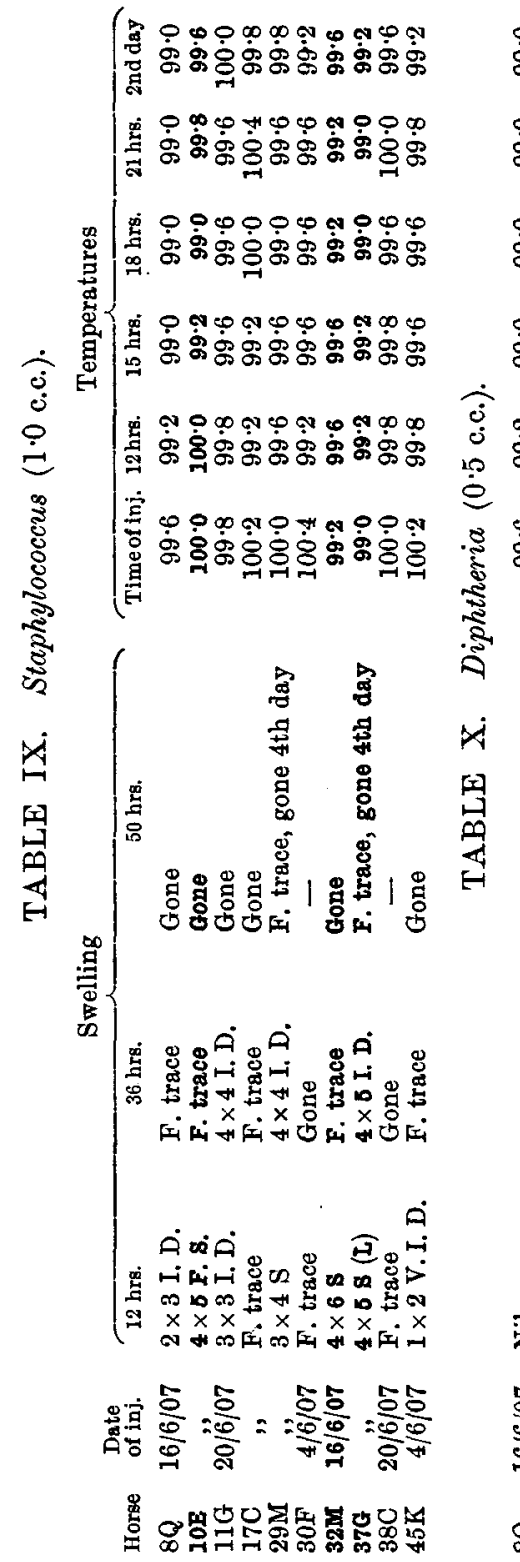

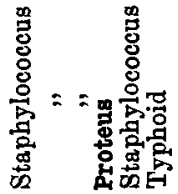

मா

$0000 \div 0$

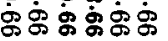

0

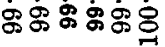

0.00000 க்க்

ㅇำ த்த்

영영영영영

$00 \infty \infty 0 \infty$ த்ட்

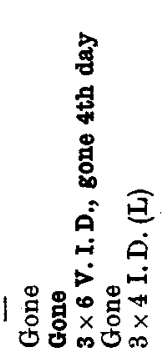

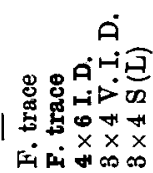

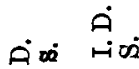

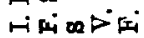
$400 \% \times+1$
$4 \times x \times x$

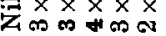

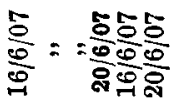

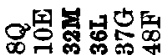

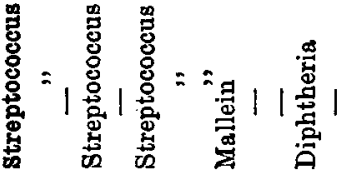

.

-

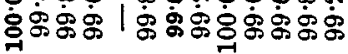

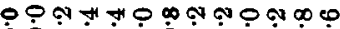

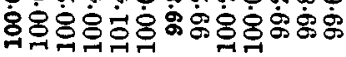

象

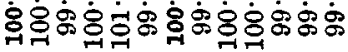

-

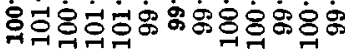

نे

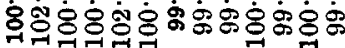

000000000000\%

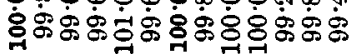

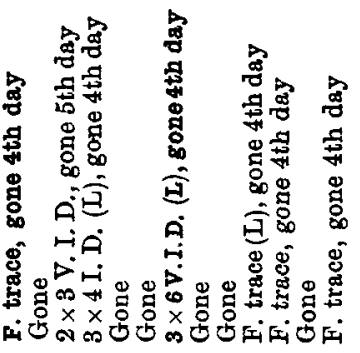

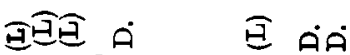

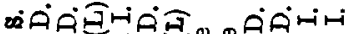

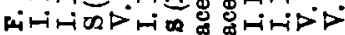

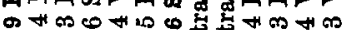
or क

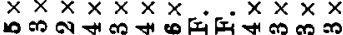

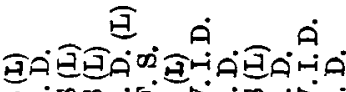

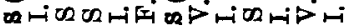
$\times \times \times \times \times \times \times \times \times \times \times \times \times$ 藏

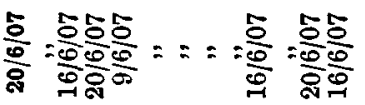

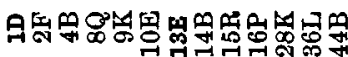




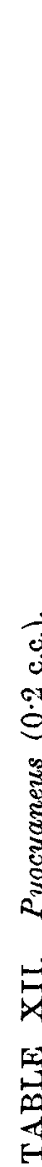

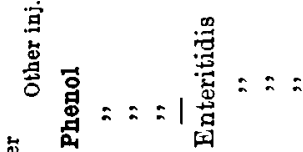

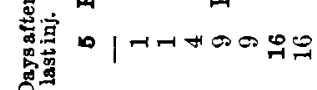

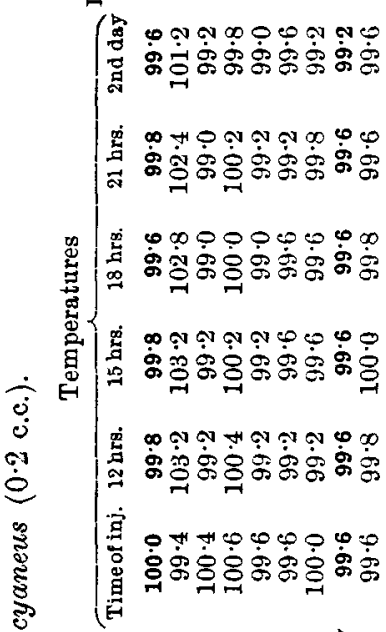

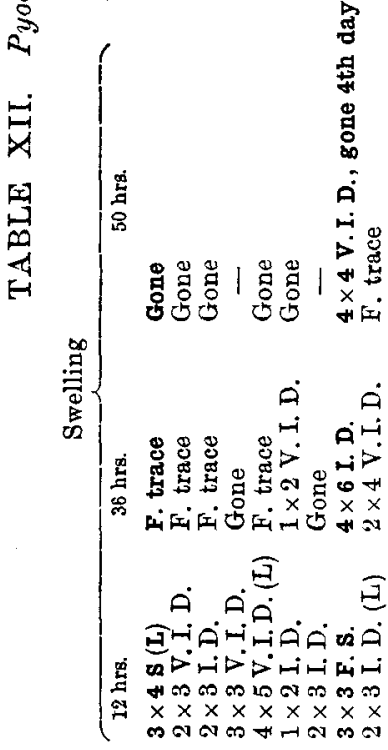

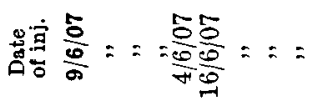

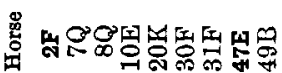

Journ. of Hyg. vil

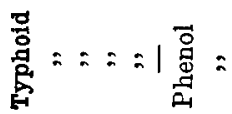

$020200 \times 10$ स

0

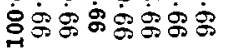

بأب

H

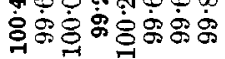

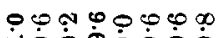

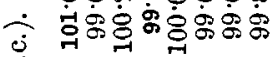

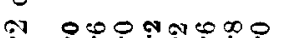

仓 芯

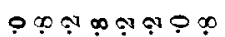

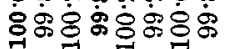<smiles>c1ccccc1</smiles>

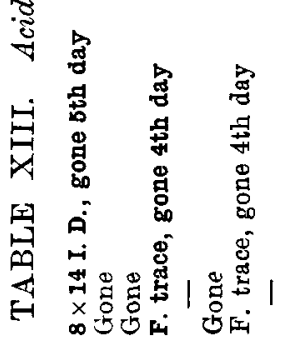

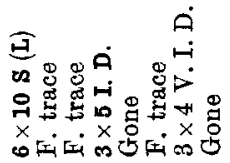
봉

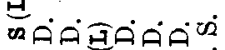

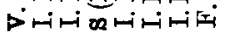

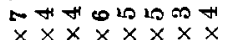

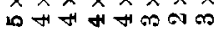

$\frac{5}{\frac{5}{0}}==:=\frac{50}{\frac{5}{0} \frac{0}{0}}=$

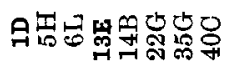

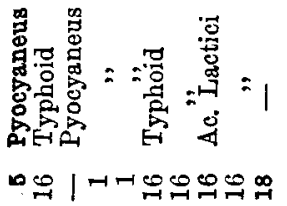

D.

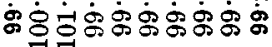

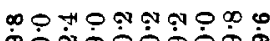
த்

த்

n ח

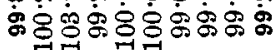

م த்

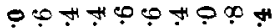

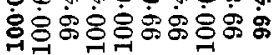

बे

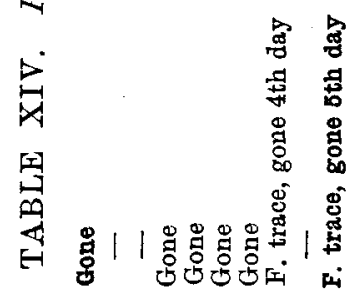

焉

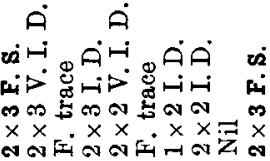

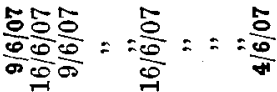

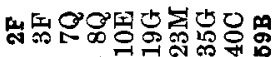


Other substances.

The effect of an irritant other than a bacterial product was next tested upon normal and immune horses. One c.c. of $2.5 \%$ phenol was used and the results are recorded in Table XIV. Two horses alone (Nos. 2 and 59) gave only moderate swellings, while well immunised horses such as 10,19, 23, and 40 gave no reaction. Apparently irritants do not act in the same way as bacterial products; slight reactions may sometimes occur, due to the susceptibility of certain horses to particular substances.

\section{Temperature Reaction.}

In two cases only after injection of other bacterial products than mallein was there any marked rise in temperature: horse 2 injected 30/5/07 with proteus and Streptococcus products, and horse 7 injected 9/6/07 with Pyocyaneus and phenol. The curves in these two cases are similar to those obtained with mallein upon horses 27,30 , and 39 .

\section{Conclusion.}

Bacterial products act similarly to mallein in giving large local reactions upon certain immune horses. As a general rule, the products from different organisms act similarly, but there are often exceptions. Table XV gives a summary of the results obtained. It will be seen that the horses that reacted to mallein react to the majority of the other products; a few horses like No. 10 are inconsistent in their reactions, but others like Nos. 13 and 14 are quite uniform.

In our experiments no connection can be traced between the reaction and the interval of time elapsing after the last injection received by the horse in the course of its immunisation, nor do the previous small test injections of other bacterial products appear to affect the subsequent reaction.

\section{Effect of repeated doses of mallein.}

An opportuuity arose of testing the action of repeated doses of mallein upon a glandered horse. The condition of the animal was recognised by the mallein reaction only, no clinical signs of glanders being present. This horse was kept carefully isolated while receiving doses of mallein every four to seven days. The opportunity was also seized of finally injecting a dose of tuberculin with the result that a large reaction was obtained. Upon post-mortem examination the lungs of the horse were found to contain only a few small nodules. It would 
H. J. Südmersen and A. T. Glenny

TABLE XV.

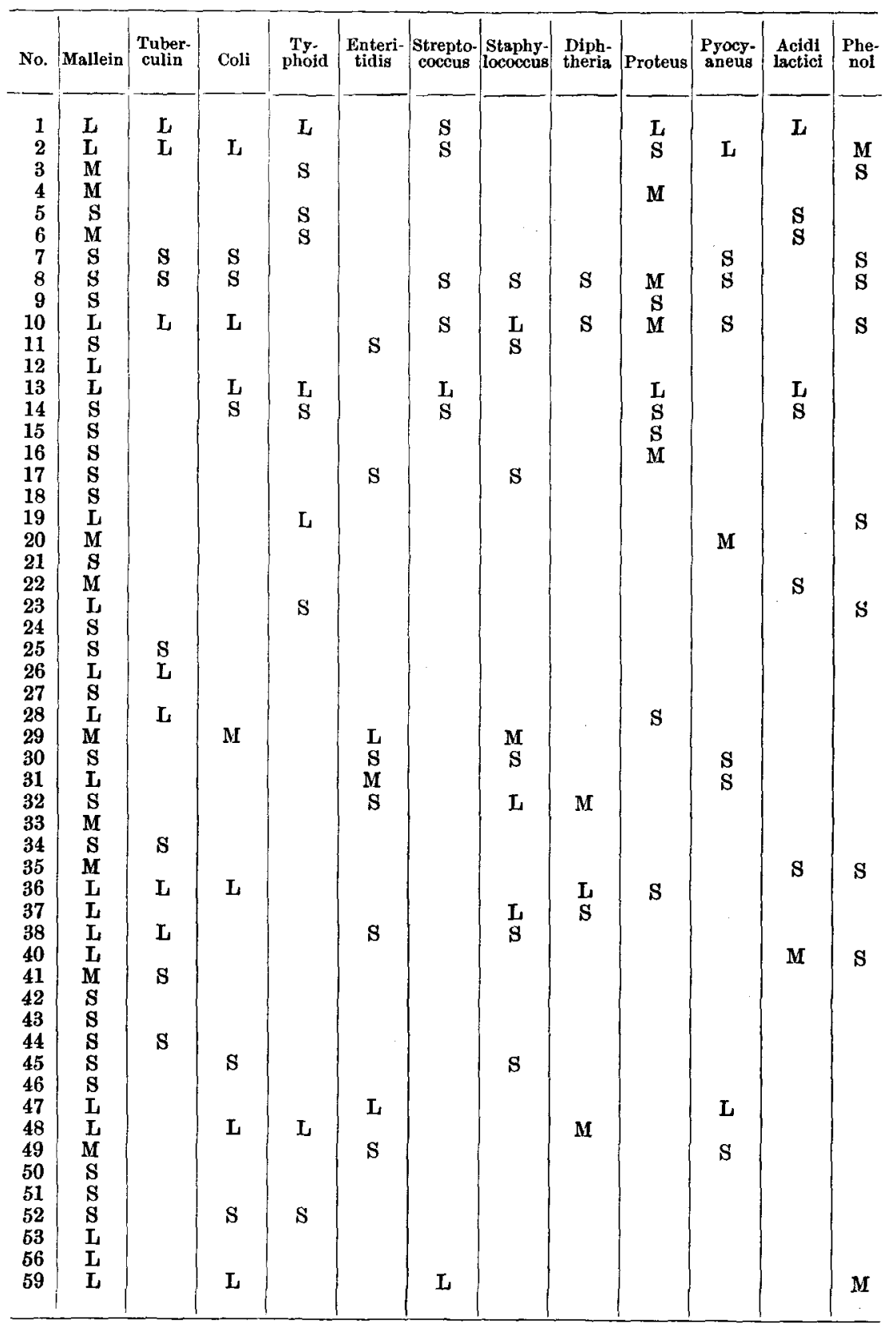

$\mathbf{L}=$ large swelling : $\mathbf{M}=$ medium swelling: $\mathbf{S}=$ small swelling. 
be interesting to conduct further researches upon the action of various bacterial products on a number of glandered horses, but unfortunately for obvious reasons this is practically impossible.

At the same time a number of normal horses were injected with mallein every four to seven days.

The general indications were:

1. A glandered horse can be injected within a few days after the first injection and still give a reaction. The dose need not be increased.

2. Healthy horses give increasing reactions upon repeating the dose at short intervals up to about the $4 \mathrm{th}-5$ th injection, but these reactions simulate those obtained upon immune horses, rather than those upon glandered animals.

3. After the fifth or sixth injection the reaction again becomes small, but does not entirely disappear.

4. No temperature reaction was obtained either in the glandered horse or in the non-glandered ones after the second dose of mallein.

\section{Summary.}

1. Many horses immunised against other bacteria or bacterial products will give a large local reaction to mallein, but this is usually not associated with a rise in temperature. In the case of horses injected with diphtheria toxin, the size of the swelling appears to be related to the degree of immunity attained. This point has not yet been established in the case of horses immunised against other bacterial products.

2. This local reaction disappears rapidly and can thus be distinguished from the reaction in the case of glandered horses.

3. In the few cases when a rise in temperature took place (3 cases out of 56) the curve was markedly different from that obtained in the case of glandered animals.

4. Other bacterial products react similarly to mallein upon immune horses. 